\title{
Integrated series active filter for aerospace flight control surface actuation
}

\author{
D Ganthony, C M Bingham \\ THE UNIVERSITY OF SHEFFIELD \\ Department of electronic and electrical engineering \\ Mappin street \\ Sheffield, England \\ Tel.: +44 / (0) - 1142225045 . \\ E-Mail: elq03dg@sheffield.ac.uk \\ URL: http://www.shef.ac.uk/eee/research/emd
}

\section{Acknowledgements}

The authors acknowledge the support of the UK Engineering and Physical Science Research Council (EPSRC), for provision of a research studentship.

\section{Keywords}

Active filter, Aerospace, Harmonics, Power Quality, Three-phase system.

\begin{abstract}
The paper investigates integrated series active filters to satisfy aircraft power quality benchmarks and underlying design compromises. Advantages include reduced component count and retrofitting capability. Further insights into the merits of the proposed solution are included, along with representative results from a prototype system.
\end{abstract}

\section{Introduction}

The advent of the more-electric aircraft has initiated significant research into the impact of on-board power quality requirements, with key emphasis on systems that must accommodate high power transient demands and noise/quality sensitive loads, such as those characteristic of actuation systems. Moreover, voltage and current distortion increases network electrical stresses and reduces generation efficiency, requiring excessive peak-to-mean electrical ratings of components, and reduced overall mass density - a premium constraint for aerospace solutions.

Power quality indicators have been considered in [1-4], and can be measured using various metrics. Here, power factor and relative harmonic magnitudes will be specifically considered. Although total harmonic distortion (THD) is a well-recognised power quality indicator, it is not considered here since the contribution of individual harmonics is of key importance.

For industrial applications, the commonly used specification (IEEE 519-1992) [1] defines allowable harmonic magnitudes. However, for aerospace applications there is no such dominant specification. Three have been considered for this paper $[2,3,4]$ that differ in how the maximum harmonic currents are defined. In [2], the harmonics are defined with respect to the present fundamental current. In [3], the harmonics are defined with respect to the full load current. The difference between [2] and [3] is that the loads in [3] are variable where as in [2] the loads are expected to operate at a constant power-there is therefore no requirement to use full load current in the definition. In [4], the harmonic load is defined in terms of the voltage distortion that it will produce. The maximum harmonic currents for a load will be dependent on the supply impedance. This will vary with position on the ac bus bar and with the state of the power network. The number and size of the loads connected to the power network will also have an affect on the harmonic currents that a single load may draw. 
This degree of freedom in the harmonic limits makes [4] unsuitable for developing single loads, where in-depth knowledge of the entire power network and its load profiles are unknown. It will increase in importance as the system characteristics are defined, and as individual elements are coupled together.

Major differences between aerospace systems and traditional industry applications are the frequency and the level of the supply. For industry, the commonly used specification (IEEE 519-1992) allows harmonic currents to be drawn in an attenuated 6-pulse shape [1]. That is, the $5^{\text {th }}$ and $7^{\text {th }}$ are the largest and, with increasing harmonic number, the allowed magnitude decreases. A similar shape is defined by $[3,4]$, but with different harmonic magnitudes. In [2], standard converters are expected to provide a 12-pulse waveshape for equipment with ratings below $5 \mathrm{kVA}$, and 18-pulse for equipment above $5 \mathrm{kVA}$. The harmonic current that can be drawn is defined with respect to the level of the fundamental, hence, harmonic limits are defined as a relative percentage.

In the absence of a definitive harmonic standard, [2] is used by virtue of providing the most stringent low-order harmonic limits (that are the most difficult to attenuate). Harmonic limits for aerospace systems are developed, generally, for constant load systems, such as those for fans or pumps. Here, however, a variable speed actuator for flight control surfaces, is considered - the load profile thus being predominantly of low holding power, with infrequent high deployment power transients. The system must therefore react quickly to changes in load, but also have a suitable harmonic content over the whole load range. This is particularly important with the prospect of using multiple, distributed, small-scale electric actuators in place of single large-scale hydraulic counterparts, whereby the multiple loads may draw a distorted current with a relatively small resultant fundamental resulting in failure to meet quality requirements. In the current absence of published limits of harmonic content levels over a range of load conditions, the harmonic limits will be calculated with respect to the full load currents.

\section{Choice of active solution}

Various active solutions for reducing harmonic levels have been investigated and previously reported $[5,6]$. To aid assessment of the various solutions, similar technologies are grouped together. The first sub-division is conveniently drawn between active filters and active rectifiers - the former being used to attenuate already existing harmonic currents, whilst the latter are designed to draw currents with low harmonic distortion. Here, active filters are considered due to their suitability for retrofitting to existing systems. The primary advantage of active filter solutions is that the current drawn can be actively controlled to be predominantly sinusoidal from a distorted supply, thereby reducing the total supply harmonic level with respect to the fundamental. A relative disadvantage, however, is that the required switching frequency of the inverter is high due to the requirement for countering the harmonics.

Active filters can be sub-divided into two broad categories; series and shunt, with the choice often being dictated by the expected load characteristics [7]. If a voltage source load is present, a series active filter is preferred, whilst a shunt active filter is considered appropriate for current source loads. For this reason, series active filters are considered the most appropriate technology here. A variant of the traditional series active filter is an integrated series active filter with a double series diode rectifier [8]. The component count in this case is reduced by combining the active filter's and the main rectifier's dc links, removing the requirement of a separate low power rectifier to charge the active filter dc-link, and reducing the number of dc-link capacitors. The circuit contains a 12-pulse transformer rectifier unit (TRU) rather than the standard 6-pulse diode rectifier. The 12-pulse TRU eliminates the $5^{\text {th }}$ and the $7^{\text {th }}$ harmonic currents from the supply. With the two lowest order, and typically dominant, harmonics, sufficiently reduced, the active filter demands are significantly lowered.

Here, the proposed circuit includes a standard 6-pulse diode rectifier, since the inline star-delta transformer of a 12-pulse solution, will necessarily increase the size and weight of the overall system. 
The disadvantage of the proposed circuit is that the active filter will have to be rated at a higher level in comparison to the 12-pulse solution.

\section{Integrated series active filter circuit}

The proposed solution consists of a three-phase integrated series active filter with 6-pulse diode rectifier, constructed from $3 \times \mathrm{H}$-bridge converters, controlled by $20 \mathrm{kHz}$ pulse width modulation (PWM). The supply network is at a fixed frequency of $400 \mathrm{~Hz}$, with a line impedance of $24 \mu \mathrm{H}$ and a resistance of $6 \mathrm{~m} \Omega$. The dc-link has a $1500 \mu \mathrm{F}$ capacitor - the load is up to $5 \mathrm{~kW}$. To reduce the impact of high-frequency PWM, an LC low pass filter is included on the output of each H-bridge. A block diagram of the system is given in Fig. 1.

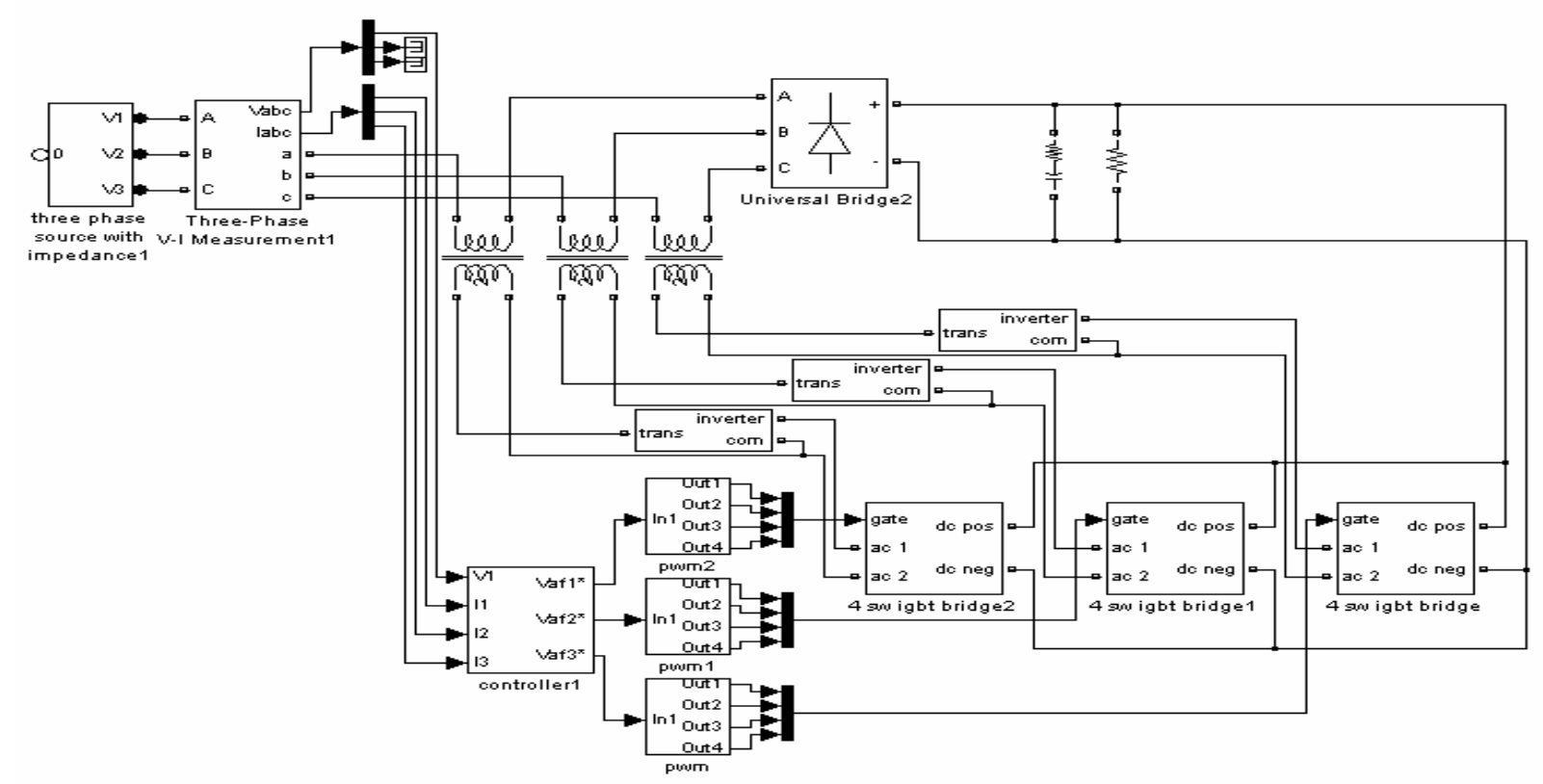

Fig. 1: Model of the integrated series active filter with 6-pulse diode rectifier.

The active filter is controlled by the $d q$-harmonic extraction method. A block diagram of the control method is shown in Fig. 2. Once the signal is transformed into the dq reference frame a low pass filter is used to obtain the fundamental current component. When the dc component is transformed back into the normal $a b c$ domain it can be subtracted from the original signal to leave the harmonic components.

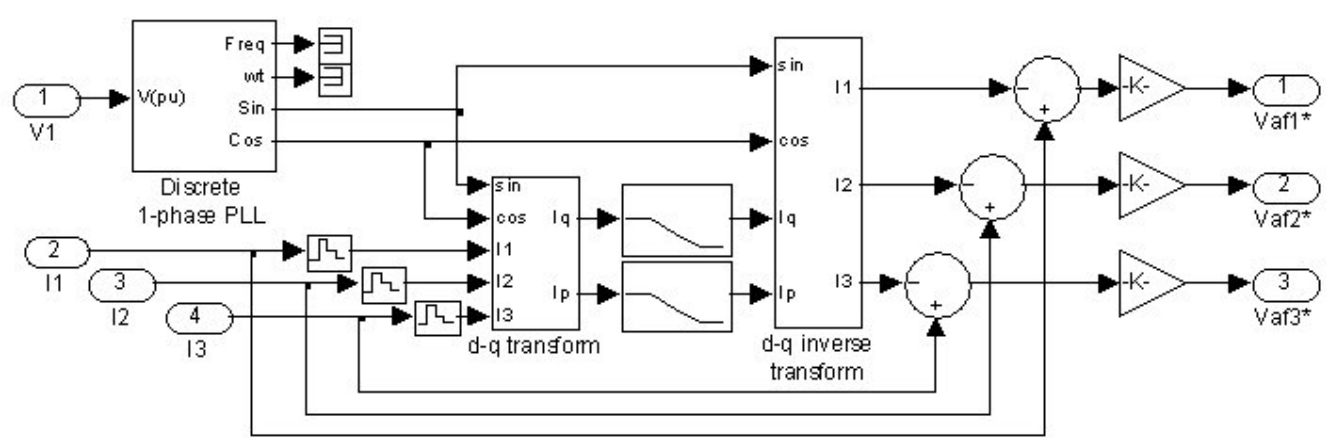

Fig. 2: DQ method control diagram.

As stated in [9], delay in the control circuit can cause system instability. To minimise delays in the practical solution, the number of clock cycles that occur between the current signal being read and the PWM control signal being output, needs to be as low as possible. This is facilitated by use of the 
control method described previously (low pass filtering) rather than obtaining the harmonic content by high-pass filtering in the $d q$ domain. Although the two methods ultimately result in the same output, the high-pass filter method requires two transformations, and a filtering operation, incurring further phase shift to obtain the harmonic signals. Here then, the proposed method obtains the harmonic signals by one set of subtractions. Any delays that are incurred during the fundamental extraction will be minimal compared to the period of the signal, so they have minimal effect on the operation of the control.

A further advantage of the proposed $d q$ transform technique, as opposed to the traditional band pass filter approach, is that it can be readily extended for use with variable frequency supplies - a feature likely to be incorporated into future electric aircraft generation systems, and one which cannot be readily accommodated by passive, or other active filter solutions.

The required voltage to attenuate harmonic currents is less than the maximum achievable from the active filter inverters, enabling the matching transformers to be of step-down type, as seen from the perspective of the active filter. A step-down transformer has the advantage that the active filter can be rated for a lower current. Moreover, parasitic voltages at the active filter side will be reduced when referred to the line side. The turns ratio that is used is $1: 1.25$, enabling the use of relatively high gains to attenuate the supply harmonics.

\section{DC link voltage control}

Initial simulation studies indicated that, due to fundamental voltage drops across the active filter, the resulting dc link voltage would be lower than desired. To counteract this effect, an additional control loop is included - see Fig. 4. The voltage drop over each transformer is measured the fundamental component is extracted using a low pass filter in the $d q$ domain. The signal is then scaled and added to the current compensation control signal.

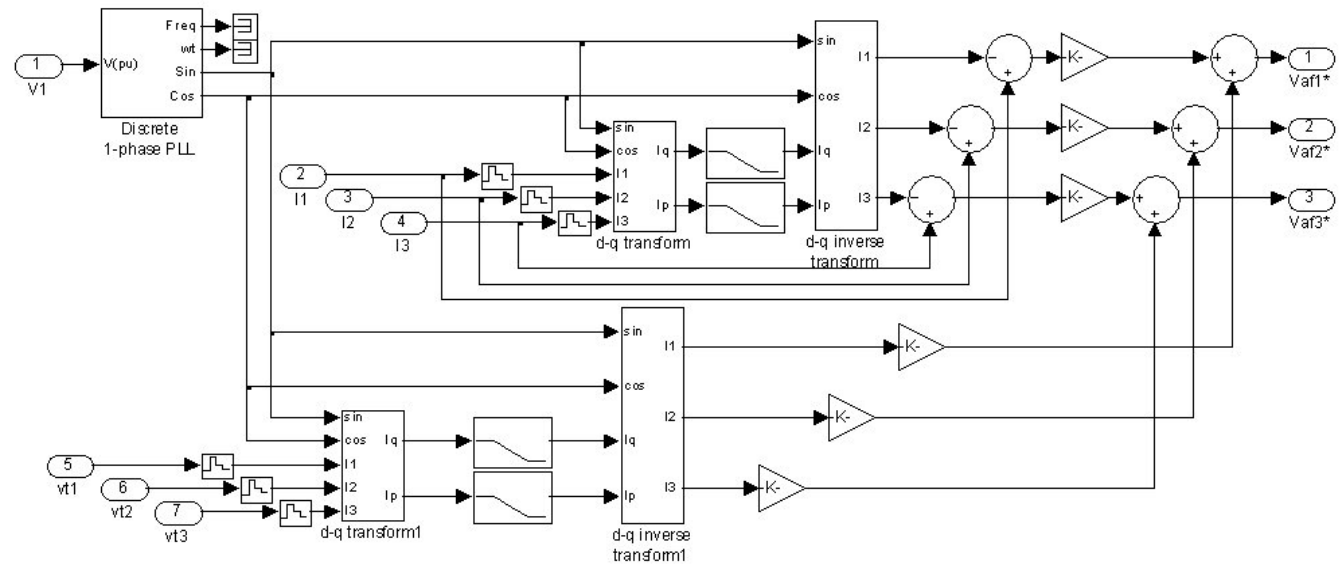

Fig. 4: DQ method with voltage and current compensation control diagram.

The active filter generates an 'in-phase' fundamental voltage, that aids the fundamental current. The effect of the voltage compensation is to increase the dc link voltage from $190 \mathrm{~V}$ to $250 \mathrm{~V}$ in this case, Fig. 5. It should be noted that this method is only of limited effectiveness, however, due to the increased load presented by the compensation system.

For the favoured PM brushless machines that are designed for control flight surface actuators, reduced weight is a key issue, and often results in high-speed solutions with low phase inductance. For such systems, high dc-link voltages can cause current control stability problems, and, indeed, in some circumstances, can prevent starting on full-load, due to the high peak-to-mean current ripple. Control of the dc-link voltage, to a lower value at low speeds may therefore be a valuable consideration, and one which this topology of converter may provide a solution. 


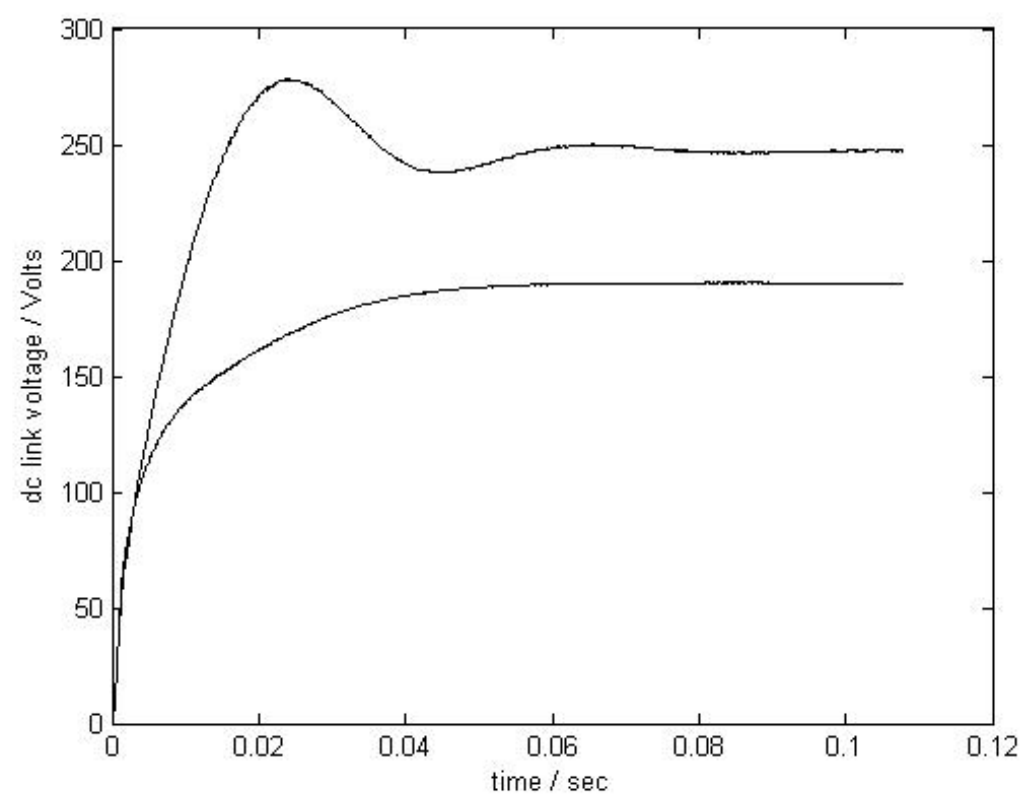

Fig. 5: dc link voltages with and with out voltage compensation.

\section{Simulation results}

The simulations were conducted at 1 -and $5-\mathrm{kW}$ loads to confirm the suitability of operation of the proposed solution at low (holding) and at high (deployment) loads. It can be seen from Fig.6 that the full load current spectrum satisfies the harmonic limits specified in [1].

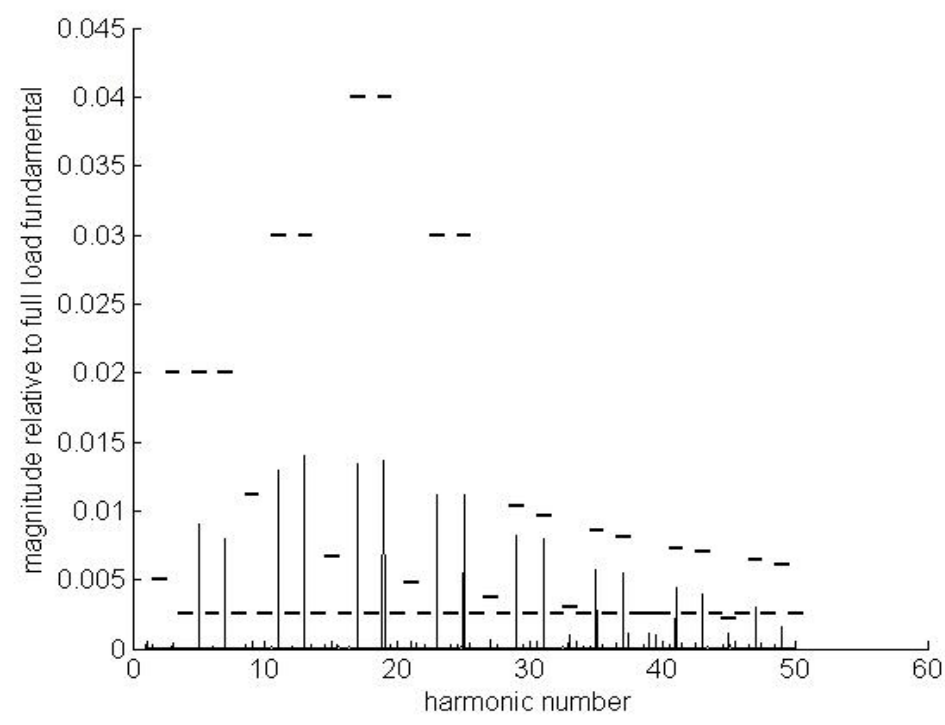

Fig. 6: harmonic current spectrum for a $5 \mathrm{~kW}$ load with respect to full load fundamental current, with harmonic limits from [1].

The harmonic spectrum for low load current with respect to the full $(5 \mathrm{~kW})$ fundamental current also satisfies the specified limits—see Fig. 7. 


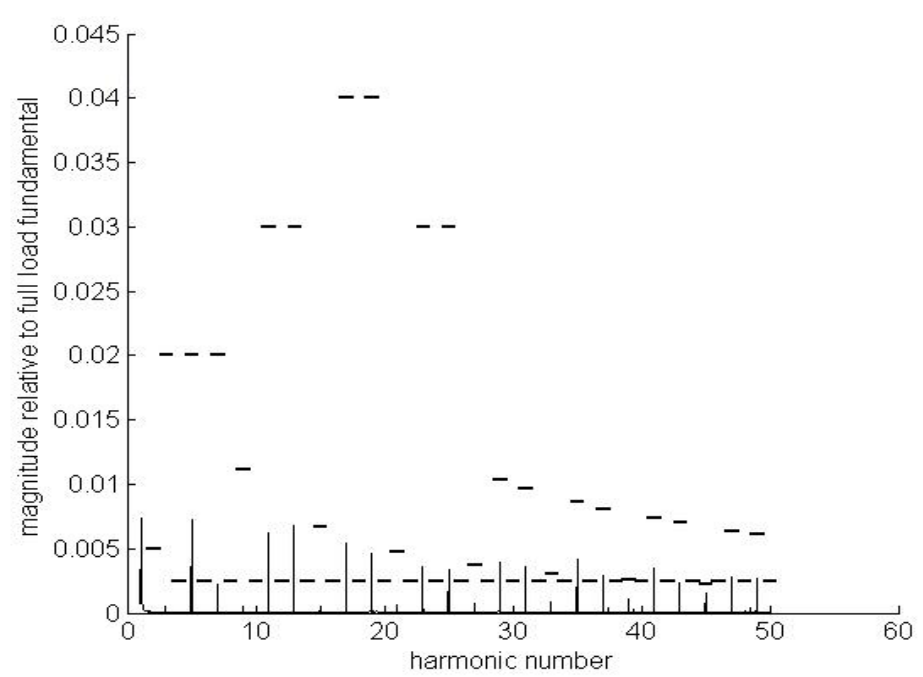

Fig. 7: harmonic current spectrum for a $1 \mathrm{~kW}$ load with respect to full load fundamental current, with harmonic limits from [1].

Transient load operation occurs during a flight profile for a control surface actuator. It is therefore important that the proposed solution reacts quickly to such transients. Consequently, the load is stepped from a low $1 \mathrm{~kW}$, in steady state, to full $5 \mathrm{~kW}$ in 0.1 seconds, and then back to $1 \mathrm{~kW}$ at 0.4 seconds, to test the transient response of the system. The resulting de link voltage is initially oscillatory, Fig. 8, although the oscillations are quickly damped in the case of low to high load, 0.1 seconds after the transient, and for the high- to low-power transient, 0.2 seconds afterwards. The degree of the transient, and its impact, is dependent on line impedance and loading of other systems, and is beyond the scope of this current paper-it is the subject of on-going investigations.

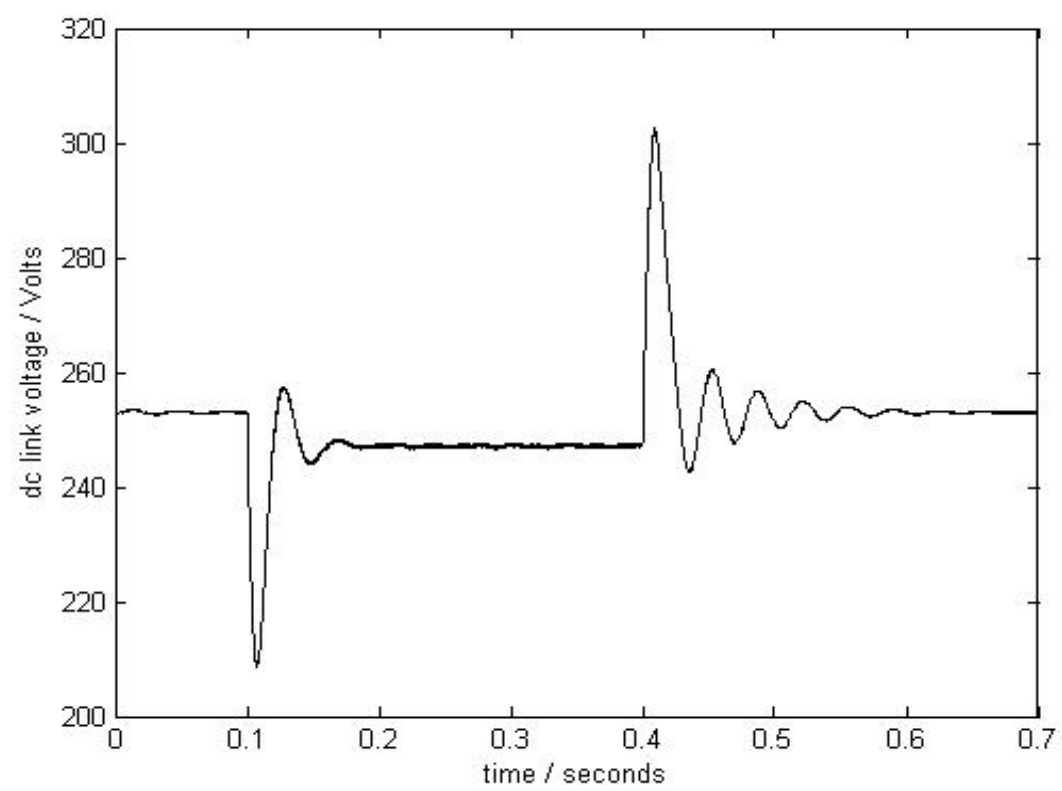

Fig. 8: dc link voltage during step transients in load power.

From the results, it is evident that the proposed integrated series active filter can operate satisfactorily at both high $(5 \mathrm{~kW})$ and low $(1 \mathrm{~kW})$ powers, and can cope adequately with transients between the two load levels. 


\section{Experimental results}

The circuit and control system is realised using a TMS320F2812 eZDSP hardware development platform. The inverters are constructed from SKM 50GB063D Semikron inverter legs, each rated for $600 \mathrm{~V}$ and 50A, and using Semikron skyper 32 two-channel driver boards, as shown in Fig. 9.

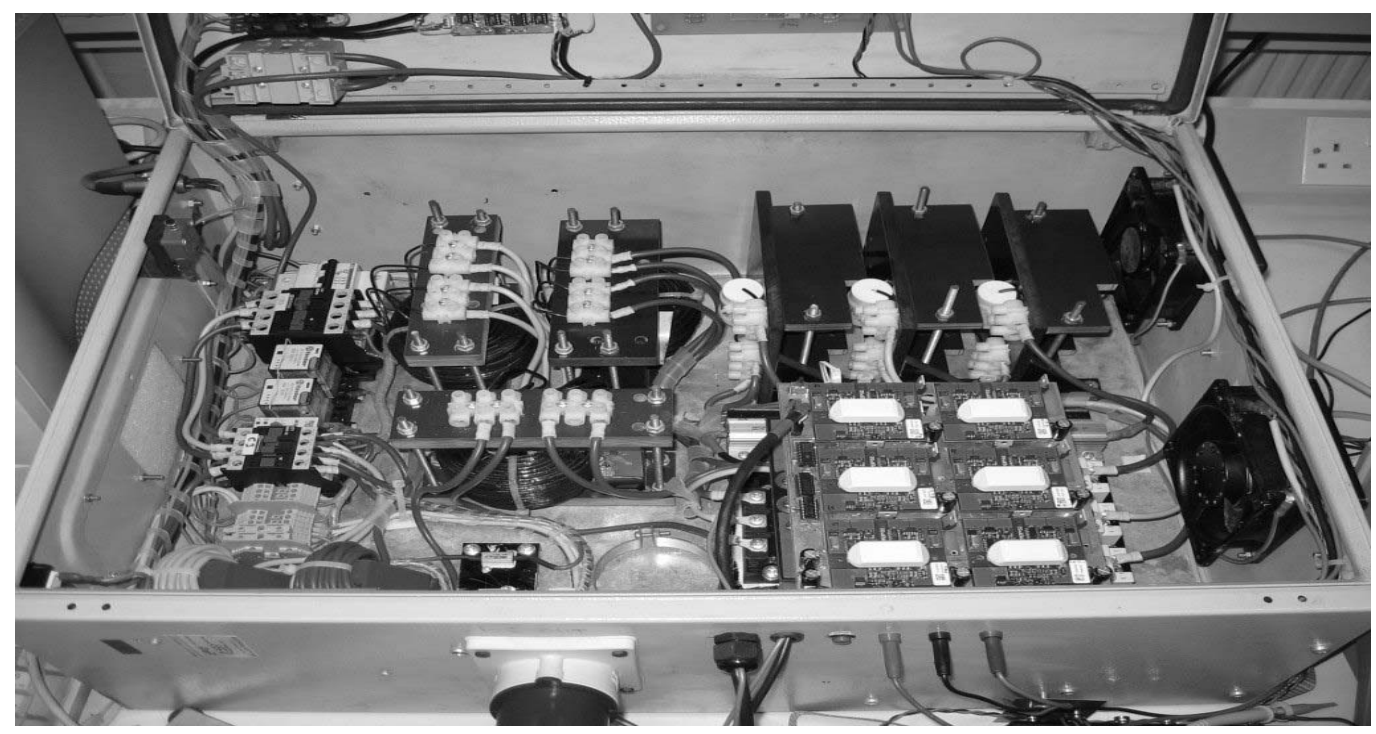

Fig. 9: Integrated series active filter with 6-pulse diode rectifier.

As previously discussed, minimum delays in the control circuit is critical to the stable operation of the active filter. The delay due to the DSP between starting an analogue to digital conversion of the input signals and outputting a PWM reference level is $2.6 \mu \mathrm{s}$. The PWM control signals can only be updated at the peak (and trough) of the triangular modulating waveform i.e. at $60 \mathrm{kHz}$. To minimise delay the analogue to digital conversion is triggered $2.6 \mu$ s before the triangular waveform can be updated. The delay associated with the hardware between the DSP and the IGBT gate is $2.8 \mu$ s, giving a total delay between starting to read in the signals and starting to control an IGBT of 5.4 $\mu$ s. The PWM control signal is updated at $60 \mathrm{kHz}$, limited by the IGBT switching frequency, resulting in a possible delay between $5.4 \mu$ s and $22.1 \mu \mathrm{s}$.

The stability criterion from [9] is rearranged in (1) to give the maximum control loop gain,

$$
K<\frac{\pi * L}{2 * \tau}
$$

$K$ is the current control loop gain, $L$ term is the system inductance, and the $\tau$ term is the delay. It can be seen from (1) that, for a given gain, the inductance and the delay are proportional. The inductance will have impedance to the fundamental current. Consequently, as the inductance is increased the regulation of the system will degrade, resulting in a lower dc-link voltage that effectively reduces the gain of the active filter. The choice of the inductor size is dependent on the minimum allowed dc-link voltage at full load power. This therefore defines the maximum current-loop control gain for the active filter. Due to the use of the outer voltage control loop, a larger inductor can be employed whilst simultaneously delivering a satisfactory dc-link voltage. The ability to include large inductor values is important in this solution due to the high gains that are required in conjunction with the delay of the control system.

\section{Passive filter design}

Thus far, the inductor has been considered as a means of maintaining system stability, however, its primary value is in the reduction of switching frequency distortion. The corner frequency of the low 
pass filter needs to be as low as possible to attenuate the switching frequency to the greatest extent, and as high above the highest harmonic to be compensated, as possible. If a phase shift is present in the active filter signals, poor compensation will occur, and reduces system stability. The choice of the corner frequency therefore becomes a trade-off between the level of attenuation of the PWM frequency and the phase-shift produced in the active filter signals. For aerospace applications, this trade-off is of particular importance due to the higher fundamental frequency i.e. from $50 / 60 \mathrm{~Hz}$ to $400 \mathrm{~Hz}$, whilst the maximum IGBT switching frequency will remains relatively constant. Here then, the switching frequency is $30 \mathrm{kHz}$ and the chosen corner frequency is $10 \mathrm{kHz}, 25^{\text {th }}$ harmonic.

The ratio between the capacitor and the inductor is also of importance. The larger the capacitance, and hence, the lower the resulting inductance, the greater the load the active filter presents to the dc link. Therefore, again it is preferable to utilise the largest possible inductor and the smallest capacitor, whilst maintain the desired level of dc link voltage.

\section{Triplen harmonics}

During testing of the integrated series active filter, triplen harmonics are evident as a consequence of the magnetising currents in the transformer core [11]. Due to its structure, the integrated series active filter is unable to directly compensate for the triplens since they are in-phase with one another. Hence, when converted to the $d q$ domain, they cancel and don't appear in the control signals. To limit the magnitude of the current triplen, three trifilar wound inductors are situated on the same core. When the currents through each inductor are balanced, three-phase, and with $\pm 120^{\circ}$ phase shift, the net flux in the core is zero.

\section{Outer control loop voltage gain}

The outer control loop is used to compensate for fundamental voltage drops across the active filter, thereby allowing higher inductor values, and, in turn, higher current loop gains to be employed. The results of including voltage loop gain are shown in Fig. 10. The inductor value is $3.1 \mathrm{mH}$ and the load is $30 \Omega$. It can be seen that with the introduction of only a small amount of voltage loop gain the resulting dc-link voltage is significantly increased. It can also be seen that the relative impact of the voltage loop gain, on dc-link voltage, reduces as the gain is increased. This is expected and is a consequence of the increased load that the active filter presents to the dc-link, thereby incurring an increased in the supply current and a higher voltage drop across the active filter.

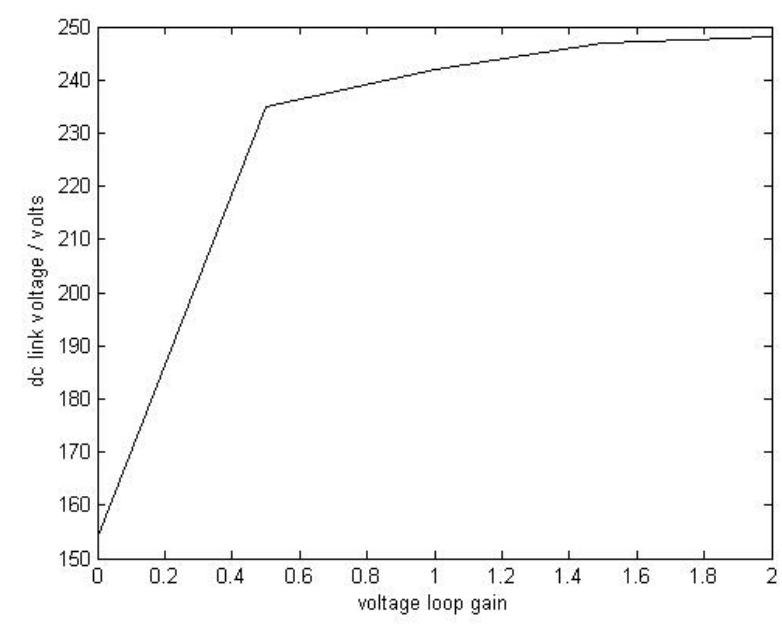

Fig. 10: de link voltages at versus voltage loop gain. 


\section{Current spectra}

The current spectra of the supply is shown in Fig. 11. In this case, the dc-link voltage is controlled to be $220 \mathrm{~V}$ with voltage control loop gain of 0.5 .

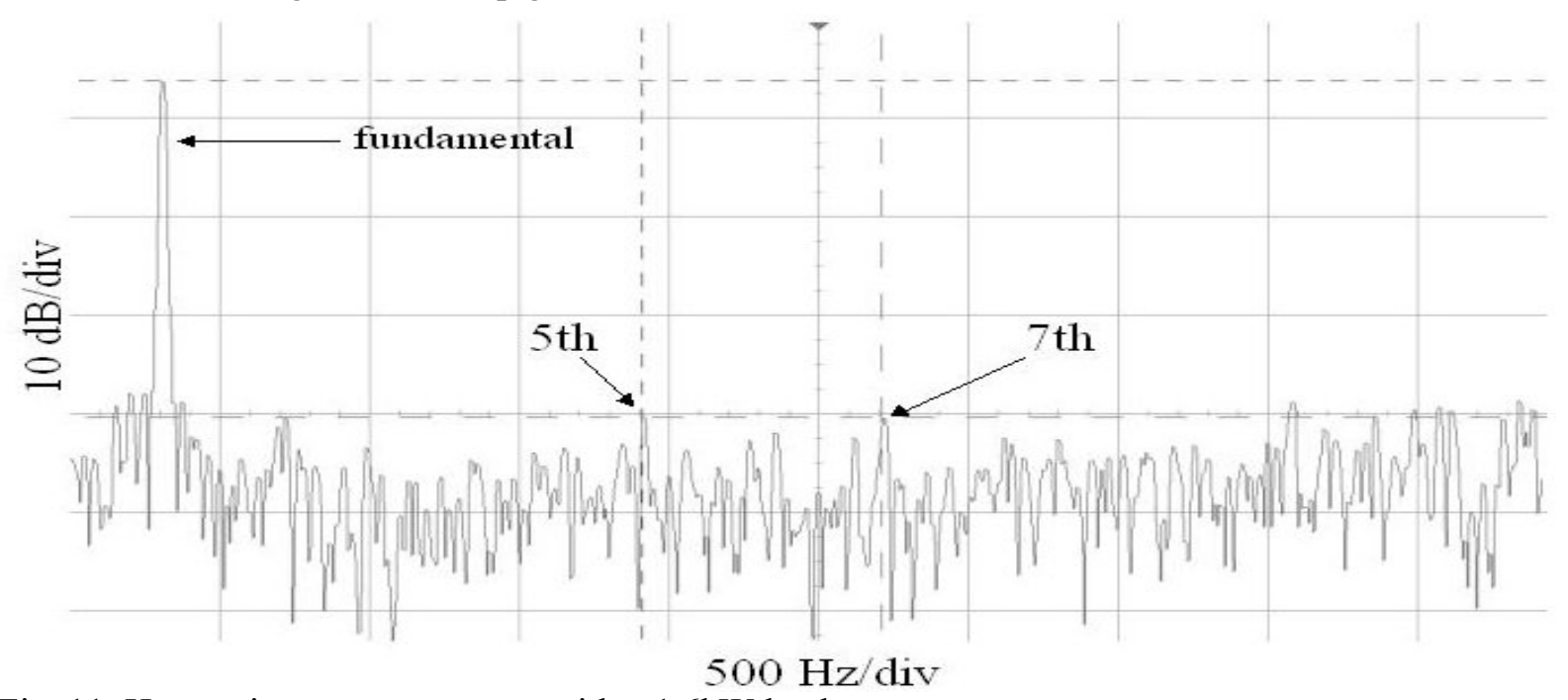

Fig. 11: Harmonic current spectrum with a $1.6 \mathrm{~kW}$ load.

The large peak shown on the left of Fig.11 is the fundamental component, with a magnitude of 3.75 $\mathrm{dB}$. The two dashed vertical lines are placed at the $5^{\text {th }}$ and the $7^{\text {th }}$ harmonics, which have similar magnitude of $-30.435 \mathrm{~dB}$. This gives a magnitude relative to the fundamental of $1.95 \%$. The low order current harmonics therefore satisfy the specified limits $(2 \%)$ for aerospace systems.

\section{Conclusion}

An integrated series active filter with 6-pulse diode rectifier has been investigated for its suitability for use with aerospace variable speed drives for flight control surface actuators. It has been shown in simulation that the proposed solution is capable of improving the harmonic content of the supply current to within specified levels, at both fully and low loads. It was also seen that the dc link voltage remained stable during step change transients between the two load levels.

Finally, using an experimental system, it has been shown that the proposed solution is practically capable of drawing supply currents with a harmonic current within the specified levels.

\section{References}

[1] Paice D A., "Power electronic converter harmonics: multipulse methods for clean power", IEEE press, pp. 7, 1995.

[2] Matheson E, Karimi K, "Power quality specification development for more electric airplane architectures", Society of automotive engineers, 2002-01-326.

[3] SAE aerospace standard, minimum performance standards for aerospace electrical power converters, AS4361.

[4] Department of defence interface standard, aircraft electrical power characteristics, MIL-STD-704E.

[5] Singh B, et al, "A review of three phase improved power quality AC-DC converters", IEEE Transactions on industrial electronics, Vol. 51, No. 3, June 2004.

[6] Kolar J W, Ertl H, "Status of the techniques of three phase rectifier systems with low effects on the mains", $21^{\text {st }}$ INTELEC, June 6-9 1999, Copenhagen Denmark.

[7] Peng F Z, "Application issues of active power filters", IEEE Industrial applications magazine, Vol. 4, No. 5, September/October 1998, pp $21-30$.

[8] Fujita H, Akagi H, "An approach to harmonic current free ac/dc power conversion for large industrial loads: The integration of a series active filter with a double-series diode rectifier", IEEE transactions on industry applications, Vol. 33, No. 5, September/October 1997.

[9] Srianthumrong S, Fujita H, Akagi H, "Stability analysis of a series active filter integrated with a double series diode rectifier", IEEE transactions on power electronics, Vol. 17, No.1, January 2002.

[10] Arrillaga J, Watson N R, "Power system harmonics", John Wiley and sons Ltd, pp. 62, 2003. 